\title{
CULTURA, REPRESENTAÇÃO E IDENTIDADE NO FUTEBOL: O ESPORTE NA ÓTICA DO PERTENCIMENTO E PATRIMÔNIO
}

\author{
Vinícius Triches
}

\begin{abstract}
RESUMO
Introdução: Considerado o esporte mais popular do mundo, o futebol é cada vez mais observado em seus elementos principais, estes sendo vistas através das partidas, territórios, rivalidades, sentimentos e outras formas de expressão associadas. Objetivo: Perceber determinados elementos da identidade, representação e cultural popular vinculados ao esporte, adotando as noções de pertencimento clubístico e patrimônio. Método: Foi realizada pesquisa exploratória, de acordo com o alcance de desenho, e pesquisa bibliográfica, quanto aos procedimentos técnicos. Resultados e Discussão: $O$ pertencimento clubístico consolida-se com a adesão ao clube, escolha esta que determinará uma identidade ao torcedor cujo vínculo será exclusivo e imutável. Tal vínculo será reforçado pela representação afetiva do seu patrimônio, constituído de elementos que devem ser defendidos, aceitos e acreditados permanentemente. Conclusão: Independente das polêmicas momentâneas, das posições pessoais relativas ao papel exercido pelo esporte na esfera social, é imprescindível reconhecer que o futebol é um elemento importante para a compreensão das diferentes realidades sociais, visto os variados olhares possíveis a partir do universo futebolístico.
\end{abstract}

Palavras-chave: Cultura, Representação, Futebol, Patrimônio, Pertencimento.

1 Universidad Argentina John F. Kennedy (UK). Endereço: Calle Piedras 655. Buenos Aires, Argentina.

E-mail: tigerconsultoriaacad@gmail.com

\section{CULTURE, REPRESENTATION AND IDENTITY I SOCCER: SPORT FROM THE POINT OF PERFORMACE AND HEREDITAGE.}

\begin{abstract}
Introduction: Considered the most popular sport in the world, football is increasingly observed in its main elements, these being seen through the matches, territories, rivalries, feelings and other associated forms of expression. Objective: Understand certain elements of identity, representation and popular culture linked to sport, adopting the notions of club membership and patrimony. Method: Exploratory research was carried out according to the scope of the design and bibliographic research regarding the technical procedures. Results and Discussion: Club membership is strengthened by joining the club, which will determine an identity for the fan whose bond will be unique and unchanging. This bond will be reinforced by the affective representation of its patrimony, consisting of elements that must be defended, accepted and permanently believed. Conclusion: Regardless of the momentary controversies, personal positions regarding the role played by sport in the social sphere, it is essential to recognize that football is an important element for the understanding of different social realities, considering the varied perspectives possible from the football universe.
\end{abstract}

Keyword: Culture, Representation, Football, Patrimony, Belonging.

Universidad Argentina John F. Kennedy (UK). Endereço: Calle Piedras 655. Buenos Aires, Argentina. E-mail: tigerconsultoriaacad@gmail.com 


\section{CULTURA FUTEBOLÍSTICA, PERTENCIMENTO E PATRIMÔNIO}

\section{INTRODUÇÃO}

Importante campo de observação da realidade social e humana, o desporto é cada vez mais um objeto de interesse do ambiente acadêmico, com base nos estudos e pesquisas referenciados em trabalhos relacionados às mais diferentes áreas do conhecimento humano. Neste universo, o futebol é campo árduo para a efetivação de pesquisas que envolvam as áreas médicas, humanas e sociais, dentre outras.

Considerado o esporte mais popular do mundo, o futebol é cada vez mais observado em seus elementos principais, estes sendo vistos através das partidas, territórios, rivalidades, sentimentos e outras formas de expressão associadas ao mesmo. Assim, torna-se um objeto relevante de estudo para a compreensão de diferentes realidades sociais visualizadas nos variados cantos do planeta.

É dentro dessa perspectiva que o presente estudo teve como objetivo fundamental analisar determinados elementos da identidade, representação e cultura popular vinculados ao esporte, sendo os escolhidos as noções de pertencimento clubístico e patrimônio. Com base nesta perspectiva, é possível entender melhor a relação entre o futebol, os clubes e os torcedores destes segundos citados.

$O$ presente artigo divide-se em quatro partes. A segunda destaca o método de pesquisa adotado no trabalho. A terceira parte apresenta os resultados e discussões. Por fim, a quarta e última parte destaca as conclusões principais.

\section{MÉTODO}

Realizou-se pesquisa exploratória, de acordo com o alcance de desenho, e pesquisa bibliográfica, quanto aos procedimentos técnicos. Gil (2014) menciona que uma pesquisa bibliográfica é aquela que é desenvolvida a partir de material já elaborado, sendo estes principalmente os artigos científicos e os livros, onde sua principal vantagem seria 0 fato de permitir ao pesquisador a cobertura de uma gama de fenômenos muito mais ampla do que aquela que a pesquisa direta poderia proporcionar.

\section{RESULTADOS E DISCUSSÃO}

O pertencimento clubístico como modalidade de identidade social: a perspectiva do torcer no universo futebolístico
Relevante papel no estudo da relação entre os torcedores e os clubes de futebol tem sido dado nos últimos anos pelo graduado em Educação Física, mestre e doutor em Antropologia Social, professor Arlei Sander Damo, vinculado a Universidade Federal do Rio Grande do Sul (UFRGS). O autor destaca a ideia do torcer como um sinônimo de pertencer, ou seja, ao se torcer por um clube, o indivíduo acaba por se tornar uma parte deste, criando-se a partir daí toda uma série de vínculos emocionais e afetivos.

O pertencimento clubístico seria, na ótica de Damo (2005), uma modalidade de vínculo identitário específico da órbita do futebol, onde seu amálgama seria a fidelidade clubística, compreendida como o valor incorporado a cultura futebolística que acabaria por atravessar as fronteiras geográficas e sociais.

Damo (2002) destaca inicialmente uma analogia para buscar compreender melhor o papel do esporte no dia-a-dia do brasileiro. Para este, o futebol cumpriria a mesma função que o vestuário, especialmente para os homens no Brasil. Isto se daria pelo fato de que o entretenimento com as questões do futebol é algo tão corriqueiro no país que acaba por ser algo absolutamente natural. Tal realidade faria com que "em um país em que a rua é um espaço privilegiado na socialização dos meninos e que o futebol é uma das brincadeiras preferidas, desdenhá-lo equivale a andar nu" (DAMO, 2002, p. 11).

Esta relevância se daria porque a partir do futebol se pode pensar a vida social dos brasileiros, dado que este está sempre presente no cotidiano dos diferentes meios de comunicação, sendo comentado pelos "especialistas" no assunto, ao mesmo tempo em que é uma pauta permanente de conversas informais entre amigos, familiares, conhecidos e desconhecidos. Assim, indo de um extremo ao outro, é um esporte que permite que até os mais humildes cidadãos possam expressar a sua opinião, a sua subjetividade, de acordo com Damo (1998).

O autor também se preocupa em entender porque 0 futebol chegou a ter a importância que tem na vida dos brasileiros. Para tanto, resgata duas linhas de pensamento que visam a responder a esse questionamento, explicando a importância do esporte como um dos símbolos da identidade nacional. 


\section{CULTURA FUTEBOLÍSTICA, PERTENCIMENTO E PATRIMÔNIO}

Considerando inicialmente uma razão instrumental, a primeira linha é aquela que estabelece uma relação direta entre as regras simples e a facilidade na improvisação com as condições de vida precária da maioria dos brasileiros. Para o autor, tal visão é equivocada, visto que no Brasil sempre existiram regiões com realidades sociais bem diferentes onde a popularidade do futebol sempre aconteceu. Logo, não haveria uma relação entre a prática do esporte com a pobreza. Também deve ser levado em conta que as regras futebolísticas acabam por se tornar fáceis por elas fazerem parte do processo de socialização do brasileiro, principalmente quando se observam os meninos.

Já a segunda linha de entendimento deste processo passa pela relação entre o futebol e a cultura popular, onde o fato do desporto ser praticado com os pés (em contraste com os demais esportes) faz com que haja um vínculo com a cultura da valorização do baixo corporal e as metáforas que exaltam o baixo ventre. Tal perspectiva, mencionada principalmente pelo sociólogo Gilberto Freyre (autor da obra-prima brasileira "Casa- Grande e Senzala"), também não avança muito em explicar o fenômeno, dado que outros países também passaram por processos semelhantes.

É desta forma que caberia mais perceber uma abordagem que levasse em consideração os contextos históricos e sociais em que houve a apropriação de uma prática inicialmente exógena e que posteriormente foiIhe atribuído um significado próprio, dado que esta é uma questão complexa, segundo Damo (2002).

Retomando a atualidade da questão diária, o futebol, para quem gosta do mesmo, não se relaciona somente com a questão da sua prática ou outro tipo de aproveitamento cotidiano ou eventual, como acompanhar notícias ou conversar com amigos e parentes, mas se dá normalmente através de um referencial. Este processo seria a escolha de um "clube do coração", momento que, pela "necessidade de optar", acaba-se tratando de uma profissão de fé, sendo esta necessária para a participação na vida social. Os clubes seriam, dentro desta lógica, uma categoria de entendimento.

Na mesma linha de Damo, Reis (2006) vai destacar que a paixão por um clube de futebol é algo que acompanha os indivíduos desde a primeira infância, sendo que torcer por um time é normalmente algo que é herdado dos pais desde o nascimento.

É dentro desta perspectiva que Damo (2008) vai buscar então compreender o que é um clube de futebol e as formas de associação e relacionamento que este vai proporcionar aos indivíduos de forma isolada e coletivamente. Para tanto, destaca que o clubismo foi o que acabou por gerar um público fiel que acabou proporcionando a expressiva popularidade alcançada pelo esporte. Assim, podem ser distinguidas duas fases neste processo evolutivo: o amadorismo e o profissionalismo.

A primeira fase foi o momento da diáspora esportiva, onde os clubes representavam importantes centros do ideal romântico dos esportes. Os momentos posteriores, já na segunda fase, proporcionaram inúmeras transformações no que se refere às formas de praticar a atividade, bem como aos seus valores, fazendo com que a importância dos clubes só tenha aumentando a partir daí.

O termo clubismo se caracterizaria então, desde este momento, como o de um vínculo exclusivo e imutável, entre torcedor e clube, que se expressaria por um sistema complexo e articulado de diferentes crenças e práticas que irão contra a lógica moderna de rompimento de vínculos de acordo com interesses momentâneos e individualistas, dado que os laços que permeiam o futebol, uma vez que sejam estabelecidos, se tornam perenes e inquebráveis, de acordo com Damo (2005).

É desta forma que quando se observa a situação específica do futebol percebe-se que um clube é um tipo de instituição política e administrativa que tem como responsabilidade a organização de uma equipe que irá competir com outras, sendo, portanto, uma competição entre clubes. Mas e as relações de pertencimento como são trabalhadas na esfera do clube? De acordo com o autor: 


\section{CULTURA FUTEBOLÍSTICA, PERTENCIMENTO E PATRIMÔNIO}

[...] os clubes precisam integrar os membros da comunidade afetiva que gravitam no seu entorno e preservar a memória da instituição - criar símbolos de identificação, relembrar conquistar importantes, etc. De outra parte, eles são como totens, entidades de natureza simbólica que condensam a representação de uma dada comunidade de sentimento, cujo sentido é em grande parte constituído pela existência de outras comunidades do mesmo gênero (DAMO, 2008, p. 143-144).

A noção de um clube ser uma comunidade de sentimento se perceberia por este ser um mediador entre uma equipe de 11 (onze) atletas e os torcedores, dado que ali está um significante, representado por aspectos como um time, uma camiseta, as cores, bandeira e os outros torcedores, e um significado, cuja âncora estará sempre em sentimentos como o amor e ódio, a entrega, a paixão, a fidelidade e o pertencimento, segundo Damo (2005). Percebe-se então que, do ponto de vista dos clubes, a adesão de sua torcida se constituirá em uma modalidade de capital simbólico, onde é mais do que importante o vínculo permanente, sendo este um capital afetivo.

Dado que os torcedores não vão a um estádio de futebol ver um jogo qualquer, mas sim ao jogo de seu clube, a torcida irá esperar sempre dos atletas que usam a camiseta de seu clube que façam isto de forma satisfatória, não apenas atendendo a critérios técnicos e táticos, mas também através de "[...] outros atributos visando atender às demandas emocionais dos torcedores" (DAMO, 2005, p. $61)$.

Dentre os critérios desta escolha por torcer ou pertencer, na perspectiva de Damo (2002), é que esta opção, que acaba por mobilizar diferentes laços de sociabilidade mais próximos, uma vez que tenha sido realizada, não pode mais ser alterada. Tal decisão de escolher pela torcida por um determinado clube não tem relação então com uma escolha momentânea, cabendo ao torcedor o ônus da opção.

O pertencimento ao clube é visto, de acordo com Damo (2008), como uma modalidade de dom sagrado, o que faz com que não seja justificada uma troca de clube, "[...] reforçando no plano afetivo as solidariedades parentais, a ideia de que a família perde e ganha unida através do futebol" (DAMO, 2008, p. 66). Na ótica do futebol, adota-se o termo de "vira-casaca" para os indivíduos que trocam de clube, aspecto este que tem conotação desmoralizante na esfera social.

Toda a herança deste pertencimento clubístico significa, para o torcedor engajado, em uma aceitação permanente dos "altos e baixos" do desempenho do seu time, ou seja, se num domingo o torcedor tem uma alegria pela vitória, esta já pode ser substituída por uma tristeza, visto que seu clube perdeu na quarta-feira seguinte. Tal processo é repetido, ao longo dos tempos, de forma indefinida.

É neste sentido que para o autor torcer é o mesmo que pertencer, visto que, de forma literal, o torcedor acaba sempre por "[...] fazer parte, tomar partido, assumir certos riscos e vivenciar situações agradáveis ou frustrações" (DAMO, 2002, p. 12). Obviamente que tal processo tem sempre uma relação com a importância e o significado que é assumido pelo futebol e a paixão clubística na vida de cada um destes pertencedores.

Outro aspecto interessante da relação entre o torcedor e o clube de futebol é que muitas vezes a paixão do primeiro pelo segundo acaba desafiando máximas populares como a que diz que "gostar de futebol pressupõe entender de futebol", o que acabaria por demandar a prática do mesmo, bem como o estudo teórico, para este entendimento das questões associadas ao esporte. Assim, é extremamente comum no Brasil, mas também em outros países que o futebol é o esporte principal, que pessoas com escassas ou até nenhuma prática do futebol acabem por se declararem torcedoras fanáticas da seleção nacional ou clube. Esta realidade corrobora uma tese de que a opção clubística é algo que transcende até ao próprio futebol, sendo uma interrogação ainda a ser esclarecida, de acordo com o autor.

Damo (2002) menciona também que o fato de torcer/pertencer a um clube permite com que se possa participar ativamente da vida social, fazendo com o torcedor acabe construindo um tipo de identidade que vai extrapolar o indivíduo, a casa e a própria família. Isto aconteceria porque a vivência deste pertencimento se dará de forma concreta nos mais diferentes espaços: na rua, no estádio ou em qualquer outro domínio público. A identificação com os seus "irmãos", ou seja, os torcedores do mesmo clube, parece ser, desta forma, de uma maneira sempre espontânea e efusiva.

Apesar de serem cidadãos como quaisquer outros, que partilham toda uma série de dilemas sociais, os torcedores possuem o gosto pelo futebol e é através deste que acaba por se tornar público e de uma maneira peculiar alguns destes conflitos e 


\section{CULTURA FUTEBOLÍSTICA, PERTENCIMENTO E PATRIMÔNIO}

dificuldades, o que é um fator que vai justificar as rivalidades clubísticas. Algumas destas rivalidades são relacionadas à localidade de moradia do torcedor, já outras são regionais e outras até de esfera nacional. Caberia então apreender, do ponto de vista dos pertencedores, os aspectos simbólicos destas disputas, sendo que muitas destas transcendem ao esporte propriamente dito.

Tais aspectos seriam relativos ao sistema de pertences que irão sugerir e constranger determinadas atitudes. É desta maneira que "[...] se você ama o Inter, dirá o sistema, você não apenas ama o Inter acima de todos os outros clubes, mas também odeia o Grêmio e vice-versa" (DAMO, 2005, p. 70).

Como o ódio ao rival é algo próprio ao sistema, será no estádio o local onde o torcedor extravasará tais sentimentos através de xingamentos aos torcedores rivais, mas também fora deste território se percebe outras roupagens da rivalidade. Caberia então aos vencedores, em suas redes de relacionamentos sociais, a ironia ao rival, normalmente realizada através de piadas; já os perdedores têm o papel de acolher os apupos de forma amistosa, o que Ihe garantia o direito de logo a seguir, nos próximos resultados, retribuir da mesma moeda.

Tal processo acontece independente das hierarquias sociais envolvidas entre os torcedores pelo fato de que "a licenciosidade instaurada pelas jocosidades clubísticas faz do futebol um poderoso dispositivo de sociabilidade transversal, rompendo diversas hierarquias e categorias sociais" (DAMO, 2005, p. 99).

Damo (2008) vai lembrar que no clubismo, assim como no totemismo, as identidades acabam por serem diacríticas, ou seja, focadas na diferença, e os sentimentos são ancorados em oposição e ambiguidade. Pode se perceber esta realidade quando se verifica que, ao mesmo tempo em que alguns torcedores estão tristes e frustrados pela derrota de seu clube, outros estão extremamente satisfeitos e eufóricos pelo simples fato de serem torcedores rivais.

Tal realidade irá acontecer porque para o torcedor ou pertencedor este se sentirá vitorioso quando seu clube vencer e perdedor quando seu clube for derrotado, mas também pode se observar que muitos torcedores também acabam por ganhar quando o seu rival perde. Este fator reforça a questão da identidade coletiva.

Para o torcedor, o clube rival será sempre visto como o "outro lado da moeda" ou a "outra metade da laranja", na perspectiva de Morato (2005). Mesmo que muitas vezes seja negado, o rival também é mencionado por declarações ou lembranças de desinteresse que, "[...] na verdade, refletem o mais puro interesse, pois é sempre comparado ao time do torcedor" (MORATO, 2005, p. 95). Assim, acaba por ser sempre lembrado nos jogos do time do torcedor através de músicas e frases rimadas, mesmo quando se está jogando contra outros clubes.

Este fato aconteceria porque a existência do rival é o combustível para a busca de vitórias, visto que sempre haverá a necessidade de estar à frente deste e isto só pode ser obtido com os êxitos dentro de campo. Por mais que se negue ou se afirme de forma contraditória, o que se pode concluir é que o rival não pode deixar de existir justamente porque é ele que permite a existência do confronto que faz com que se possa gerar a motivação que é necessária para o crescimento e desenvolvimento da equipe, de acordo com o autor.

\section{O patrimônio do clube como elementos para 0 pertencimento do torcedor e a identificação clubística \\ Morato (2005) destaca uma série de} vínculos entre o torcedor e o seu "clube do coração", relações estas que são corroboradas muitas vezes através de símbolos que acabam por representar o patrimônio do clube como um elemento de reforço contínuo a identificação entre a torcida e o seu clube de futebol. Este patrimônio, somado aos jogadores e a própria torcida, é o que se chama da tríade fundamental do clube. Sendo os jogadores passageiros e os torcedores permanentes, a conexão entre estes dois elementos são fundamentais para o êxito do clube nas competições esportivas que irá disputar.

Todo processo de torcer por um clube passa pelo estabelecimento de vínculos, sendo estes uma construção cultural que é baseada em relações e experiências. Fatores como a influência de algum familiar ou amigo, a identificação por causa da origem ou trajetória, a proximidade local ou alguma vivência positiva ou negativa fazem com que se escolha um clube em detrimento de outro. Com base na decisão de torcer pelo clube, o indivíduo torna-se um defensor e entusiasta do patrimônio da sua agremiação.

Este fenômeno acontece porque o patrimônio do clube é o maior tesouro para o torcedor, sendo algo grande e sagrado para este. Pode-se entender o patrimônio de um clube como o conjunto de objetos simbólicos que o torcedor "[...] aprende a aceitar, a crer e a defender logo que se concretiza a sua 
escolha" (MORATO, 2005, p. 78). Considerando que a escolha de um clube é o marco de um ritual, é por ali que se suplantará a figura do indivíduo e surgirá a do torcedor. Tal patrimônio é representado então por elementos como o clube ou a sede, a história, a camiseta, a bandeira, o hino, o distintivo, o mascote, o estádio e os seus títulos.

A sede ou o clube, sendo este social ou de campo, não é considerado um patrimônio de todos os torcedores, mas somente de uma parcela destes. Os privilegiados, neste caso, são os sócios do clube, que são torcedores que pagam mensalidades para a instituição esportiva. Mesmo que os torcedores tenham preferência em irem ao estádio do que a sede, muitas vezes nem conhecendo a mesma, estes ainda têm respeito por este local, considerando como parte de seu patrimônio.

Já a história é um patrimônio guardado e normalmente sabido por todos os torcedores, visto que quem torce sempre sabe ou terá o desejo de saber as origens e o desenvolvimento do seu clube. Tal elemento é importante para a compreensão das formas de rotulação recebidas por um clube $e$, consequentemente, da sua torcida.

Também recebem importância os hinos clubísticos, sendo estas representações sonoras que exaltam e auto afirmam o patrimônio da instituição, como também servem para fomentar elementos como a garra e a fibra. São estes normalmente elementos que desempenham um papel forte na união entre os torcedores, sendo considerado para muitos como uma oração.

O mascote também é um símbolo que contribui para a identificação dos torcedores, aparecendo como um elemento que normalmente é idealizado quando da fundação ou que vai sendo incorporado através da trajetória, onde "[...] as boas características que eles apresentam são atribuídas às características do time e de seus torcedores numa idealização de estereótipo" (MORATO, 2005, p. 81).

Entretanto, o que se observa é que a camiseta e a bandeira são os maiores objetos simbólicos, dado que são eles que carregam as cores e o distintivo da agremiação esportiva.

A camiseta tem normalmente maior importância do que a bandeira para o torcedor. Isto é decorrente do fato de ser um objeto de fácil acesso (considerando a oficial e a nãooficial), sendo carregada junto ao corpo, o que faz com que seja denominado no meio futebolístico como a "segunda pele" do torcedor. O uso da vestimenta demonstra a predileção por um clube e, ao mesmo tempo, é um canal, de acordo com autor, para negar e agredir simbolicamente os demais, principalmente aqueles que são considerados rivais.

Mesmo sendo um objeto simbólico de muita importância e valorização para o torcedor, a bandeira recebe menor atenção tradicionalmente, visto que esta tem uma restrição maior no que se refere ao acesso por parte deste. Assim, acaba sendo empregada mais frequentemente somente por parte das torcidas organizadas.

Já o estádio do seu clube é cénsiderado pelos torcedores como o seu templo máximo do futebol, tendo as características de um patrimônio querido e irretocável, ou seja, um terreno sagrado. Características estas que não se direcionam ao estádio do clube rival, considerado um "[...] território profano, inimigo. Adentrá-lo requer coragem e também um bom planejamento, como numa batalha" (MORATO, 2005, p. 83).

Finalmente, os títulos podem ser considerados um patrimônio do clube porque é através deles que se materializam as vitórias no universo futebolístico, sendo motivo de orgulho para os torcedores a conquista destes. Para o autor, a conquista de um título é sempre representada pelo crescimento do patrimônio clubístico.

\section{CONCLUSÃO}

As discussões sobre o universo do futebol como importante elemento cultural da nossa sociedade parece não ter fim nos dias atuais, mesmo que já há algumas décadas tal temática seja discutida permanentemente no meio jornalístico, acadêmico e nas mesas de bares em diferentes locais do mundo.

Independente das polêmicas momentâneas dentro e fora do campo, das posições pessoais relativas ao papel exercido pelo esporte na esfera social, é imprescindível reconhecer que o futebol é um elemento importante para a compreensão das diferentes realidades sociais, visto os variados olhares possíveis a partir do universo futebolístico, sendo que alguns deles foram apresentados no presente trabalho.

Notou-se que o ato de torcer por um clube acaba por gerar uma situação de pertencimento a este por parte do torcedor, tendo como "pano de fundo" a existência de vínculos emocionais e afetivos. Tal realidade apareceria porque o pertencimento clubístico acaba por denotar uma identidade onde a principal característica é necessidade de uma fidelidade permanente. 
Dada a presença cotidiana na vida dos brasileiros em diferentes espaços sociais (família, escola, vizinhança e mídia, etc.), o esporte acaba por gerar uma necessidade por parte da maioria em escolher um "clube do coração", ao qual se determinará um vínculo exclusivo e imutável por parte do novo torcedor. Assim, será reforçado permanentemente o público fiel ao futebol e a sua própria popularidade que vai passar de geração para geração.

Com a adesão ao clube, tendo como base o pertencer e o torcer, o indivíduo logo terá uma vida social que se relacionará a agremiação, pertencendo então a uma comunidade de sentimento em que, pelo fato de pertencer a " $A$ ", deve automaticamente rejeitar "B", ou seja, o clube rival ao seu.

Também será importante a criação de vínculos por parte do torcedor para representar afetivamente este novo laço com o seu clube. É desta forma que os símbolos de representação do patrimônio do clube serão os elementos que sinalizarão a identidade entre a torcida e o seu clube nos mais diferentes lugares.

O patrimônio do clube constitui-se, então, em objetos simbólicos que o torcedor irá sempre respeitar e defender independente das situações momentâneas. Constituem-se elementos patrimoniais de um clube de futebol a sua sede, a sua história, a sua camiseta, o seu hino e o seu estádio, dentre outros.

Em linhas finais, percebeu-se que o futebol no Brasil acabou por se tornar o seu esporte mais popular independente de classe social, com representação expressiva na cultura e cotidiano nacional, sempre permeada por ações, hábitos e sentimentos que denotam o universo futebolístico, tanto no que se refere aos clubes ou a seleção.

Consideram-se como sugestões de novos trabalhos o entendimento do processo de consolidação do futebol como uma paixão nacional, tendo como foco o processo ocorrido em estados brasileiros selecionados, buscando ali apurar semelhanças e diferenças nos processos históricos ocorridos.

\section{REFERÊNCIAS}

DAMO, A. S. Para o que der e vier: o pertencimento clubístico no futebol brasileiro a partir do Grêmio Foot-Ball Porto Alegrense. Programa de Pós-Graduação em Antropologia Social (Dissertação de Mestrado), Instituto de Filosofia e Ciências Humanas, Universidade Federal do Rio Grande do Sul, Porto Alegre, 1998.

Futebol e identidade social: uma leitura antropológica das rivalidades entre torcedores e clubes. Porto Alegre: Ed. Universidade/UFRGS, 2002.

Do dom à profissão: uma etnografia do futebol de espetáculo a partir da formação de jogadores no Brasil e na França. Universidade Federal do Rio Grande do Sul, Instituto de Filosofia e Ciências Humanas. Tese (Doutorado em Antropologia), Porto Alegre, 2005.

Dom, amor e dinheiro no futebol de espetáculo. Revista Brasileira de Ciências Sociais, v. 23, n. 66, fev. 2008.

GIL, A. C. Métodos e técnicas de pesquisa social. 6. ed. São Paulo: Atlas, 2014.

MORATO, M. P. A dinâmica da rivalidade entre pontepretanos e bugrinos. In: DAOLIO, J. (org.). Futebol, cultura e sociedade. Campinas, SP: Autores Associados, 2005.

REIS, H. H. B. Futebol e violência. Campinas: Armazém do Ipê (Autores Associados), 2006. 